\title{
Changes in the pressure-volume relation of the right ventricle when its loading conditions are modified
}

\author{
A N Redington, M L Rigby, E A Shinebourne, P J Oldershaw
}

\begin{abstract}
Ventricular pressure-volume diagrams were obtained from the right ventricle in patients before and after relief of right ventricular pressure load, in patients with volume loaded right ventricles, and from the left ventricle in patients after the Mustard procedure for transposition of the great arteries. The patterns of ejection during pressure development and decline were similar in patients after relief of pressure load and in those with isolated volume load. A right ventricular pressure load, however, reduced ejection during the two "isovolumic" periods, and the overall shape of the pressure-volume loop resembled that of the normal left ventricle. Pressurevolume diagrams obtained from the left ventricle after the Mustard procedure were indistinguishable from the normal right ventricle, which accords with the hypothesis that the normal right ventricular contraction pattern is a consequence of loading conditions rather than a reflection of an intrinsic property of the myocardium.
\end{abstract}

The pressure-volume characteristics of the normal right ventricle were described in an earlier study. ${ }^{1}$ Briefly, the pressure-volume loop of the normal right ventricle is more triangular than that of the left, with poorly defined periods of isovolumic contraction and relaxation and a phase of ejection during the decline in right ventricular pressure. It was suggested that these differences were load dependent and therefore reflected the different impedance characteristics of the systemic and pulmonary vascular beds. If this were the case, then large changes might be expected when the loading conditions of the right ventricle are modified. As yet there are no data on the pressure volume relation of the human right ventricle with varying loading conditions.

We studied pressure-volume loops obtained from patients with various conditions that subject the right ventricle to differing loading conditions and from the left ventricle in patients after the Mustard operation, when the left ventricle acts as the pulmonary ventricle.
Patients and methods

PATIENT GROUPS

Group 1 consisted of 16 patients (age range 119 , median 3.5 years) with raised right ventricular systolic pressure; 10 had a diagnosis of cyanotic tetralogy of Fallot, four had valvar pulmonary stenosis, and two cor pulmonale. The mean (SD) right ventricular peak systolic pressure in this group was $58(9) \mathrm{mm} \mathrm{Hg}$.

Group 2 consisted of five patients with right ventricular volume load (age range 1.5-28, median 14 years). Three had an ostium secundum atrial septal defect and in two there was hemianomalous pulmonary venous drainage. Only patients with right ventricular peak systolic pressures of $<35 \mathrm{~mm} \mathrm{Hg}$ were included (mean 30 (6) $\mathrm{mm} \mathrm{Hg}$ ). The mean ratio of pulmonary to systemic flow in these patients was $2 \cdot 2(0 \cdot 7)$ to 1 .

Group 3 consisted of 10 symptom free patients studied 1-6 years after total correction of tetralogy of Fallot. Right ventricular systolic pressure in this group was 28 (7) $\mathrm{mm} \mathrm{Hg}$ and no residual intracardiac shunt was detected in any patient. Nine patients had undergone enlargement of the right ventricular outflow tract with insertion of a Dacron patch. Three patients had short early diastolic murmurs in the pulmonary area suggesting the presence of pulmonary regurgitation. Transannular repair (extending the patch across the pulmonary valve annulus) was not performed in any of the patients. Some of the patients in this group and some in group 1 were included in a previous study to examine other aspects of right ventricular function after repair of tetralogy of Fallot. ${ }^{2}$

Group 4 included three patients (aged 9, 9, 11 years). All had undergone a Mustard repair of simple transposition of the great arteries. After this operation the right ventricle acts as the systemic ventricle and the left ejects into the pulmonary circulation. Left ventricular pressure-volume diagrams were obtained in these three patients who had normal pulmonary artery pressures and no obstruction of the left ventricular outflow tract. The left ventricular systolic pressure in this group was 26 (5) $\mathrm{mm} \mathrm{Hg}$.

METHODS

All paediatric patients were studied during general anaesthesia with (alphaxalonealphadolone acetate, Althesin) after 


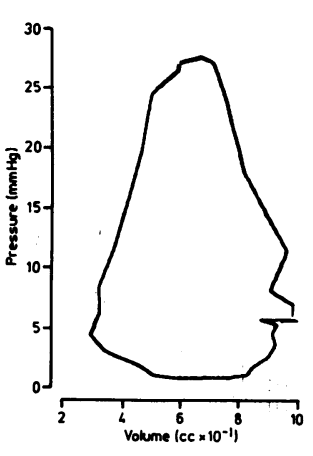

Figure 1
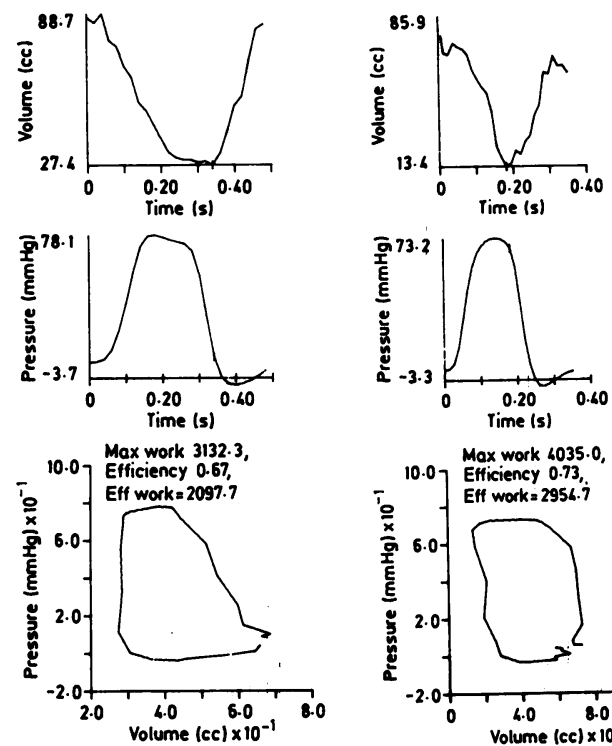

Figure 2
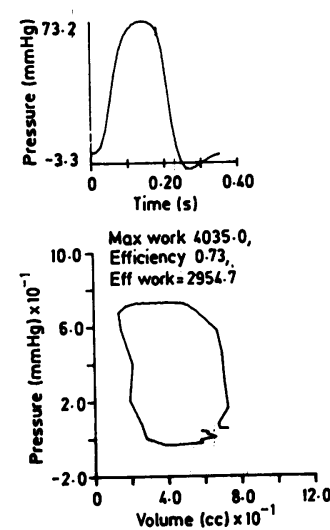

Figure 3

Figure 1 A normal right ventricular pressure-volume diagram illustrating ejection during pressure development and decline. (Taken from Redington et al, Br Heart J 1988;59:23-30, fig 4.)

Figure 3 Right ventricular pressure-volume diagram from a patient with pulmonary stenosis. There are well-defined periods of isovolumic contraction and relaxation.

Figure 2 Right ventricular pressure-volume diagram taken from a patient with tetralogy of Fallot. Ejection was occurring during pressure development but not during pressure decline. Maximum work and effective work are measured in $\mathrm{mm} \mathrm{Hg} \times \mathrm{ml}$.

premedication with trimeprazine. Adult patients were studied under local anaesthesia, without premedication. Biplane right (groups 1,2 , and 3 ) and single plane left (group 4) ventriculograms were recorded by the methods described previously. ${ }^{13}$ When the heart rate exceeded 100 beats per minute the cineframe rate was increased from 50 to 75 frames per second. Simultaneous pressure measurements were made with micromanometer tipped catheters (Millar Instruments). The electrocardiogram, cineframe marker, and event mark were recorded to enable later synchronisation of pressure and volume data.

\section{ANALYSIS}

Only normally conducted beats were analysed; extrasystoles and immediate extrasystolic beats were excluded. Only beats recorded after the end of contrast injection were examined. Ventriculograms and pressure recordings were digitised with equipment described elsewhere. ${ }^{12}$ Right ventricular volumes were corrected with the regression equations derived from cast studies. ${ }^{1}$ Left ventricular volumes were estimated from single plane ventriculograms by the area-length method. ${ }^{3}$

Pressure-volume diagrams were drawn for

each patient and the following measurements made:

(a) End diastolic volume index-that is enddiastolic volume corrected for body surface area $\left(\mathrm{ml} / \mathrm{m}^{2}\right)$

(b) Stroke volume index $\left(\mathrm{ml} / \mathrm{m}^{2}\right)$

(c) Cycle efficiency (\%)

(d) Percentage of ejection occurring during pressure rise

(e) Percentage of ejection occurring during pressure fall

The derivation of these indices has been described in detail elsewhere. ${ }^{1}$

\section{STATISTICAL ANALYSIS}

All variables were expressed as the mean (SD). However, for the purposes of comparison, we did not assume that the variables were normally distributed and we therefore compared group data by the non-parametric Mann-Whitney $U$ test. The null hypothesis was rejected if $p<0.05$.

\section{Results}

The table shows the data from all patient groups. For comparison we include our data on the normal right and left ventricle. ${ }^{14}$

\section{RIGHT VENTRICULAR VOLUMES}

These measurements were not the focus of this study and so will be described only briefly.

The end-diastolic volume index in groups 2 and 3 was higher than normal $(p<0.02$, $\mathrm{p}<0.05$ respectively) and higher than in group 1 ( $p<0.05, p<0.02$ respectively). The stroke volume index in the volume loaded group (group 2) was higher than normal (p < 0.05), but otherwise there was no significant difference between the groups. The ejection fraction in groups 2 and 3 was lower than in the normal right ventricle (both $\mathrm{p}<0.05)$.

\section{PRESSURE-VOLUME RELATIONS}

Group 1 Pressure-volume loops in patients with right ventricular pressure load were abnormal (compare fig 1 with figs 2 and 3 ). Their overall shape resembled that obtained from the normal left ventricle (fig 4). There was a well defined end systolic shoulder in all patients, with approximately $5 \%$ of ejection occurring during right ventricular pressure decline ( $p<0.001$ compared with normal). In nine patients (eight with tetralogy of Fallot and one with pulmonary stenosis) there was appreciable ( $>10 \%$ ) ejection during the pressure rise (mean change for group $=27 \%$, $\mathrm{p}=$ NS compared with the normal right ventricle). There was a significant linear relation

Data obtained from pressure-volume diagrams from each of the four study groups (mean 1SD). Data from the normal right and left ventricle are included for comparison. See text for details

\begin{tabular}{lclllcc}
\hline & $\begin{array}{l}\text { EDVI } \\
\left(\mathrm{ml} / \mathrm{m}^{2}\right)\end{array}$ & $\begin{array}{l}S V I \\
\left(\mathrm{ml} / \mathrm{m}^{2}\right)\end{array}$ & $E F(\%)$ & $\begin{array}{l}\text { Ejection pressure } \\
\text { rise }(\%)\end{array}$ & $\begin{array}{l}\text { Ejection pressure } \\
\text { fall }(\%)\end{array}$ & $\begin{array}{l}\text { Cycle } \\
\text { efficiency }\end{array}$ \\
\hline Group 1 (pressure load) & $66(17)$ & $42(13)$ & $63(13)$ & $27(19)$ & $5(5)$ & $0.74(0.07)$ \\
Group 2 (volume load) & $105(20)$ & $55(18)$ & $52(12)$ & $18(9)$ & $42(24)$ & $0.59(0.04)$ \\
Group 3 (relief of pressure load) & $92(30)$ & $48.5(16)$ & $52(6)$ & $40(8)$ & $30(9)$ & $0.55(0.01)$ \\
Group 4 (LV post-Mustard) & $56(6)$ & $37(4)$ & $66(6)$ & $26(8)$ & $36(6)$ & $0.58(0.06)$ \\
Normal RV & $64(13)$ & $43(8)$ & $62(6)$ & $39(4)$ & $43(9)$ & $0.56(0.08)$ \\
Normal LV & $61(9)$ & $47(9)$ & $77(6)$ & $4(5)$ & 0 & $0.78(0.08)$ \\
\hline
\end{tabular}

EDVI, end diastolic volume index: SVI, stroke volume index; EF, ejection fraction. 
Figure 4 A normal left ventricular pressurevolume diagram. (Taken from Redington et al, $\mathrm{Br}$ Heart J 1988;59:23-30, fig 7.)

Figure 5 Right ventricular pressurevolume diagram from a patient with a large atrial septal defect. Ventricular volumes were increased but the overall shape of the loop was similar to that of the normal right ventricle (fig 1).

Figure 6 Right ventricular pressurevolume diagram from a patient after repair of tetralogy of Fallot. Ejection was occurring during pressure development and decline.

Figure 7 Left ventricular pressure-volume diagram obtained after Mustard repair of transposition of the great arteries. The left ventricle (ejecting into the pulmonary circulation had similar pressure-volume characteristics to the normal right ventricle ( $f i g$ 1).

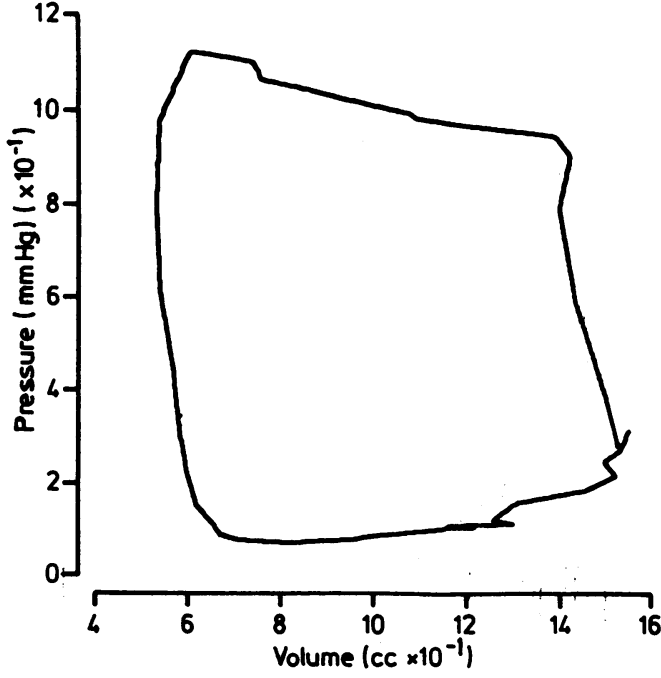

between peak right ventricular pressure and percentage ejection during the pressure rise $(\mathrm{r}=-0.65, \mathrm{p}<0.05)$.

Group 2 The shape of the pressure-volume loops in these patients with right ventricular volume load was indistinguishable from that of the normal right ventricle. Cycle efficiency and percentage ejection during pressure fall were not significantly different from normal. In one case, however, there was no ejection from the right ventricle during pressure development (fig 5). This finding remains unexplained.

Group 3 After the relief of right ventricular outflow tract obstruction there was a tendency for right ventricular end diastólic volume to increase, but this did not reach statistical significance. The loops from these patients showed significant differences, however. Cycle efficiency was lower $(p<0.005)$ as was percentage ejection during pressure fall $(p<0.005)$. There was no difference in percentage ejection during pressure rise. None of the measured loop variables was significantly different from normal. In eight of the patients the loops also showed an increase in volume during pressure fall (fig 6 ). In the absence of continued injection of contrast, filling through a ventricular septal defect, or through the tricuspid valve, this volume increase during pressure decline must represent pulmonary regurgitation. The measurement and relevance of this are discussed in a previous study. ${ }^{2}$

Group 4 Left ventricular pressure-volume loops after the Mustard operation (fig 7) showed that $26 \%$ of ejection occurred during pressure rise and $36 \%$ during pressure fall (not significantly different from the normal right ventricle). Cycle efficiency was significantly lower than that for the normal left ventricle $(\dot{p}<0.01)$ but was similar to values obtained from the normal right ventricle $(p=N S)$.

There was no significant linear relation between any of the indices measured and heart rate in any of the groups.

\section{Discussion}

The accuracy and reproducibility of our method of measuring the volume of the normal right ventricle have already been established. ${ }^{1}$ The regression equations used to correct the angiographic estimate of right ventricular volume were obtained from the study of human and animal casts of the right ventricle. In our validation studies we tried to maintain the normal geometry of the right ventricular casts, particularly the normal curvature of the interventricular septum. Pressure or volume loading, however, are likely to change the normal geometry. Indeed, numerous echocardiographic studies showed changes in right ventricular geometry, particularly the shape and position of the interventricular septum..$^{56}$ It may be incorrect, therefore, to apply these
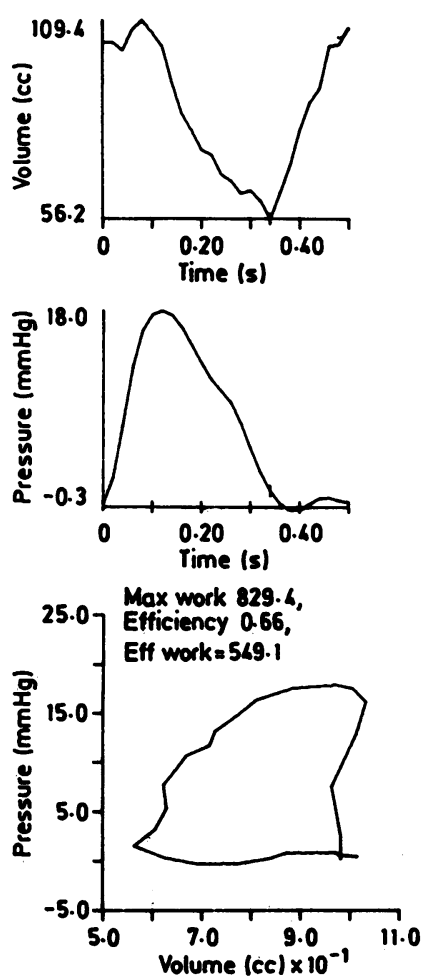

Figure 5
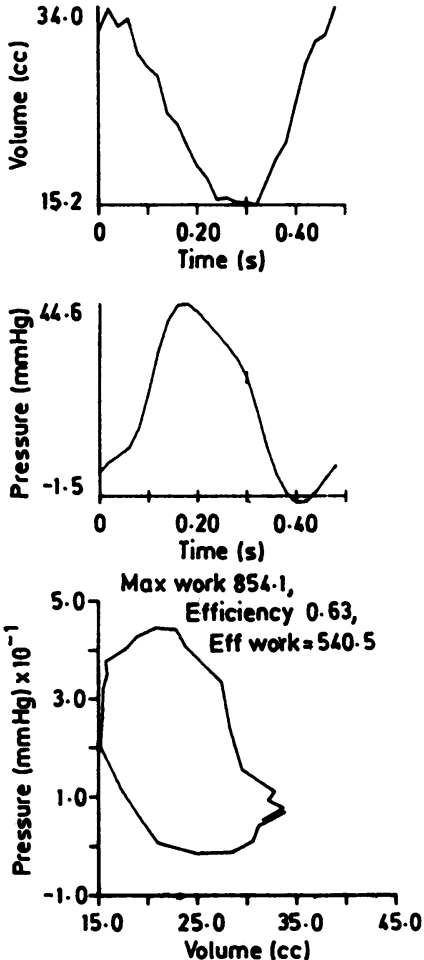

Figure 6
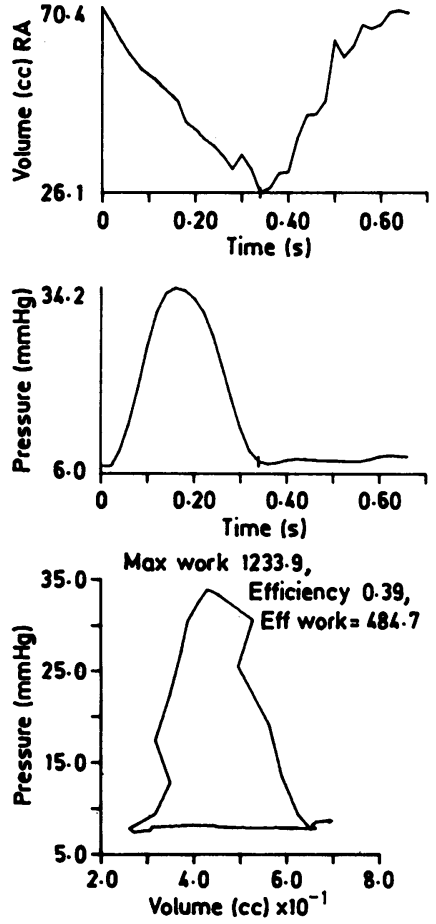

Figure 7 
regression equations, as is usually done, to the estimation of right ventricular volume in patients with pressure or volume load. Ideally regression equations appropriate to the condition being studied should be obtained by studies of postmortem casts. But such studies are almost impossible to organise. Furthermore, although absolute volume measurements may be subject to error, relative changes, frame-by-frame changes throughout the cardiac cycle for example, should be valid. There was a similar problem with measuring left ventricular volume in group 4 . In these patients left ventricular volumes were measured by the area-length method, a method which assumes that the shape of the left ventricle is a prolate ellipsoid. After the Mustard operation the normal pressure gradient from the left to the right ventricle is reversed and consequently the position of the interventricular septum changes. The right ventricle becomes more circular in cross section and the left ventricle seems to be "wrapped" around it. ${ }^{7}$ Once again the use of a method that has been validated in the normal ventricle may be inappropriate when the normal geometry changes. As with the pressure and volume loaded right ventricles mentioned above, relative changes in volume (like those measured in this study) should, however, be maintained and examination of pressure-volume loops by the measurements described in this study (all of which are independent of absolute volume) should be valid. Furthermore, despite these potential errors, when groups 1,3 , and 4 (that is patients with no intracardiac shunting, and no valve regurgitation) were compared with normal individuals there was no significant difference between measurements of stroke volume, suggesting that any error introduced was small.

The aim of this study was to document any differences between the normal right ventricular pressure-volume loop and loops obtained from the right ventricle as it is affected by changes in its loading conditions. If, as was suggested previously, ${ }^{1}$ the shape of the normal right ventricular pressure-volume loop is dependent on the low pressure, high capacitance characteristics of the pulmonary vascular bed, then large changes might be expected when these conditions change.

Group 1 consisted of patients with relative obstruction to outflow from the right ventricle. The level of obstruction varied within the group, however. It was predominantly subvalvar in those with tetralogy of Fallot, valvar in patients with pulmonary valve stenosis, and at the arteriolar level in patients with pulmonary vascular disease. Despite these differences the shape of the pressure-volume loops in these patients was remarkably consistent. In particular, the occurrence of ejection during pressure decline, which was a striking feature in the normal right ventricular pressure volume loop, was absent when there was raised right ventricular pressure. In these loops there was a period of truly "isovolumic" pressure decline. Indeed, cycle efficiency and percentage ejection occurring during pressure decline were no different from those in the normal left ventricle. One would expect from these observations that closure of the pulmonary valve would coincide with the onset of pressure decline-that is the "hangout" period, described by Shaver et al ${ }^{8}$ and discussed in detail elsewhere, ${ }^{19}$ should be shorter. This is indeed the case-the hangout period in the pressureloaded right ventricle was similar to that seen in the systemic circulation. ${ }^{8}$

The percentage of ejection occurring during the pressure rise was not significantly different from that in the normal right ventricle of these patients, however. This cannot be explained on the basis of tricuspid regurgitation, which was not seen on the angiograms. It is possible that this finding represents early systolic shunting across the ventricular septal defect from the right to the left ventricle, but again this was not obvious from the angiograms. There was, however, a significant inverse linear relation $(r=-0.65, p<0.05)$ between right ventricular systolic pressure and the percentage of ejection occurring during the pressure rise, suggesting that this is a load dependent phenomenon. The right ventricular outflow tract obstruction in tetralogy of Fallot is often predominantly subvalvar and dynamic. The peak outflow tract gradient occurs late in systole, and so another explanation may therefore be that this phenomenon represents forward flow into the pulmonary artery, which is permitted by the relatively small outflow tract gradient during early systole. So it is interesting that eight of the 10 patients with tetralogy of Fallot but only one of the remaining six patients in this group had significant ejection during pressure development.

Right ventricular pressure-volume loops from patients with volume load and after relief of pressure load had the characteristics of the normal right ventricle. Volume loading alone, without an increase in pulmonary artery pressure, led to an increase in right ventricular volume but did not influence the pattern of ejection. Similarly after relief of outflow tract obstruction the systolic portion of the loop was similar to normal.

There seems little doubt, therefore, that the normal right ventricular pressure-volume loop reflects a series of load dependent phenomena. Some of these phenomena have been observed when the loading conditions of the left ventricle are manipulated. Ejection during pressure rise occurs when there is a low pressure "run-off", in mitral regurgitation for example, ${ }^{10}$ and animal experiments have shown that with extreme afterload reduction much of left ventricular ejection can take place during pressure decline. ${ }^{11}$ After the Mustard operation for transposition of the great arteries the left ventricle ejects into the pulmonary vascular bed. Thus there is a unique opportunity to examine whether the normal right ventricular pressurevolume loop is entirely dependent on its loading conditions or whether it, in addition, reflects an intrinsic property of the right ventricular myocardium. After the Mustard operation the left ventricular pressure-volume loops were indistinguishable from those of the normal right ventricle, with similar cycle efficiency 
and percentage ejection occurring during pressure rise and fall. In another study pressuredimension loops obtained from unoperated patients with simple transposition of the great arteries (obtained by $M$ mode echocardiography with simultaneous pressure measurements) showed a similar pattern. ${ }^{12}$

What are the clinical implications of these findings? We have previously suggested that the measurement of isovolumic and end systolic indices of right ventricular contraction may be invalid because of the lack of a truly isovolumic contraction period and the lack of adherence to the time-varying elastance (E) model of contraction, upon which end systolic indices-for example $E_{\max }$-are based. A poorly defined period of isovolumic contraction remains a feature of the right ventricular pressure-volume loop when there is pressure load but an isovolumic relaxation phase and end systolic shoulder, likely to coincide with $E_{\max }$ (as in the left ventricle), can be defined. Measurement of $E_{\max }$ should therefore be possible for the right ventricle under these conditions. The slope of $E_{\max }$ is likely to be linear and vary with changes in inotropy, as has been observed for the canine right ventricle. ${ }^{13}$ However, the validity of $E_{\max }$ is based on its independence from loading conditions. In this study we have shown that this is clearly not the case, either for the right or for the left ventricle. The implications are clear. The measurement of $E_{\max }$ for the pressure loaded right ventricle should be possible, but its theoretical basis is unsound, and although they are often used to assess left ventricular contractility such measurements are open to the same criticisms as above and should be interpreted with caution.

We showed that the shape of the normal right ventricular pressure-volume loop depends on its loading conditions rather than reflecting a specific property of the right ventricular myocardium. This may have important implications for the measurement of right ventricular function.

We thank Dr D Gibson, Dr D Hughes, and Mrs S Jones for their help and advice throughout the course of this study. This work was completed while A N R was the holder of a British Heart Foundation grant.

1 Redington AN, Gray HH, Hodson ME, Rigby ML, Oldershaw PJ. Characterisation of the normal right ventricula pressure-volume relation by biplane angiography and simultaneous micromanometer pressure measurements. Br Heart J 1988;59:23-30.

2 Redington AN, Oldershaw PJ, Shinebourne EA, Rigby ML. A new technique for the assessment of pulmonary regur gitation and its application to the assessment of right ventricular function before and after repair of tetralogy of Fallot. Br Heart J 1988;60:57-65.

3 Hui WKK, Gibson DG. Mechanisms of reduced left ventricular filling rate in coronary artery disease. $\mathrm{Br} \mathrm{Heart}$ $J$ 1983;50:362-71.

4 Redington AN, Knight WB, Oldershaw PJ, Dawson DR, Shinebourne EA, Rigby ML. Ventricular function in double inlet left ventricle [Abstract]. Circulation 1986;74:I1465.

5 Tanaka H, Tei C, Nakao S, et al. Diastolic bulging of the interventricular septum towards the left ventricle. Circulation 1980;62:558-63.

6 Kieffer RW, Hutchins GM, Moore GW, Bulkley BH Reverse septal curvature. Association with primary pulmeverse septal curvature. Association with primary pul1979;66:831-6.

7 Trowitczsch E, Colan SD, Sanders SP. Global and regional right ventricular function in normal infants and infants with transposition of the great arteries after Senning operation. Circulation 1985;72:1008-14.

8 Shaver JA, Nadolny RA, O'Toole JD, et al. Sound pressure correlates of the second heart sound. Circulation 1974;49:316-25.

9 Shaver JA. Clinical implications of the hangout interval. In $J$ Cardiol 1984;5:391-8.

10 Bunnell IL, Grant C, Greene DG. Left ventricular function derived from the pressure-volume diagram. Am J Med 1965;39:881-94.

11 Weber KT, Janicki JS. Instantaneous force-velocity-length relations in isolated dog heart. Am J Physiol (H) 1977;232:241-9.

12 Hausdorf G, Gravinghoff L, Keck EW. Incoordinate contraction and relaxation in d-transposition of the great arteries with intact ventricular septum-analysis of pressure-dimension relations. Basic Res Cardiol 1986;81:134-41.

13 Maughan WL, Shoukas AA, Sagawa K, Weisfeldt ML. Instantaneous pressure-volume relationship of the canine right ventricle. Circ Res 1979;44:309-15. 